\author{
Marquette University \\ e-Publications@Marquette
}

10-1999

\title{
An XPS Study of the Radiation-induced Effect on the Thermal Degradation and Charring of Butadiene and its Copolymers
}

Jlanwei Hao

Beijing Institute of Technology

Shaoli Wu

Beijing Institute of Technology

Charles Wilkie

Marquette University, charles.wilkie@marquette.edu

Jianqi Wang

Beijing Institute of Technology

Follow this and additional works at: https://epublications.marquette.edu/chem_fac

Part of the Chemistry Commons

\section{Recommended Citation}

Hao, Jlanwei; Wu, Shaoli; Wilkie, Charles; and Wang, Jianqi, "An XPS Study of the Radiation-induced Effect on the Thermal Degradation and Charring of Butadiene and its Copolymers" (1999). Chemistry Faculty Research and Publications. 747.

https://epublications.marquette.edu/chem_fac/747 
Marquette University

e-Publications@Marquette

\section{Chemistry Faculty Research and Publications/College of Arts and Sciences}

This paper is NOT THE PUBLISHED VERSION; but the author's final, peer-reviewed manuscript. The published version may be accessed by following the link in the citation below.

Polymer Degradation and Stability, Vol. 66, No. 1 (October, 1999): 81-86. DOI. This article is (c) Elsevier and permission has been granted for this version to appear in e-Publications@Marquette. Elsevier does not grant permission for this article to be further copied/distributed or hosted elsewhere without the express permission from Elsevier.

\section{An XPS Study of the Radiation-Induced Effect on the Thermal Degradation and Charring of Butadiene and Its Copolymers}

$\underline{\text { Jianwei Hao }}$

National Laboratory of Flame Retardant Materials, School of Chemical Engineering and Materials Science, Beijing Institute of Technology, Beijing, China

Shaoli Wu

National Laboratory of Flame Retardant Materials, School of Chemical Engineering and Materials Science, Beijing Institute of Technology, Beijing, China Charles A. Wilkie

Department of Chemistry, Marquette University, Milwaukee, WI Jianqi Wang

National Laboratory of Flame Retardant Materials, School of Chemical Engineering and Materials Science, Beijing Institute of Technology, Beijing, China 


\section{Abstract}

A pseudo-in-situ XPS approach shows that cross-linking induced by irradiation may lead to char formation even though it shows only a small or no effect on the onset temperature of degradation.

\section{Introduction}

In the study of flame retardance of polymers, thermal degradation, cross-linking and charring are complex processes that occur upon heating. Cross-linking appears to be an important factor in determining the thermal stability of polymers. Cross-linking in the condensed phase has been identified as an effective means of achieving flame retardancy of polymers [1]. It has previously been shown that suitable additives to assist in the formation of char can be designed. Cross-linking does not always enhance thermal stability. Recent experimental data reported by Schnabel et al. [2] show that radiation induced cross-linking by ${ }^{60} \mathrm{Co}-\mathrm{y}$-rays or fast electrons does not affect the thermal behavior of polystyrene and play only a minor role in the cases of BD-containing polymers. The evaluation of the cross-linking density was based on Flory-Rehner theory [3]. In this paper we report on a pseudo-in-situ XPS approach for the determination of the temperature-dependent extent of carbonization which is taken as a general term, referring to simply the formation of carbon. The advantages of this approach are that one is able (i) to trace the changes in the extent of cross-linking as a function of temperature without the interference of solvent; (ii) to measure over a wide range of temperatures, e.g. from ambient up to $500^{\circ} \mathrm{C}$; (iii) to have a sensitivity that is high enough for investigation of black charred residues. We will show how cross-linking induced by ${ }^{60} \mathrm{Co}-\gamma$-rays or fast electrons affects the thermal degradation and charring of polybutadiene, polystyrene and the copolymers, K-resin and SBS, which contain styrene and 1,4-butadiene moieties.

\section{Experimental}

\subsection{Materials}

Both polystyrene and poly-(1,4-butadiene) (98\% cis) were obtained from Aldrich Chemical Company. The two copolymers, poly(styrene-co-butadiene), differ in their contents of the two components. The copolymer which is rich in styrene (75\% St/25\% BD) was a gift from Phillips Petroleum, denoted as $\mathrm{KrO1}$, and is herein referred to as $\mathrm{K}$-resin. The copolymer which is rich in butadiene (25\% St/75\% BD) was a gift from Shell Chemical Company, (Kraton D1102) and is referred to as SBS in this paper.

\subsection{Irradiation of polymer samples}

The samples B-6 (SBS, No. 4, slice, 0.15 MGy/Ar), K-5 (K-resin, No. 7, slice, 0.41MGy/Ar) and $\mathrm{K}-6$ (K-resin, No. 8, slice, 0.62MGy/Ar) were irradiated under argon in glass ampoules at ${ }^{60} \mathrm{Co}-$ $Y$-source of the Hahn-Meitner-Institut (see [2]). Samples No. 3 (SBS, thin film, 0.04 MGy) and No. 6 (K-resin, thin film, 0.04 MGy) were irradiated in air with the BF-5 linear electron accelerator at Institute of Low Energy Nuclear Physics, Normal University, Beijing. The 
operating parameters were selected as follows: energy range, $4 \mathrm{MeV}$; average current, 200 $\mu \mathrm{A}$; maximum scanning width, $600 \mathrm{~mm}$; absorbed dose rate, $100 \mathrm{~Gy} / \mathrm{s}$; and irradiated dose range, 10-100 kGy. The specimens were laid on the translational bed with homogeneous area of $120 \times 120 \mathrm{~mm}$ and the vertical distance between the edge of the titanium window and the specimen was $35 \mathrm{~cm}$.

\subsection{XPS experiments}

The spectra $\left(\mathrm{Mg} K_{\alpha}\right)$ were recorded on a PHI 5300 ESCA system (Perkin-Elmer) at $250 \mathrm{~W}$ $(12.5 \mathrm{kV} \times 20 \mathrm{~mA})$ under a vacuum better than $10^{-6} \mathrm{~Pa}\left(10^{-8}\right.$ Torr $)$ calibrated by assuming the binding energy of the adventitious carbon to be $284.6 \mathrm{eV}$. Specimen Nos. 1, 2, 3, 5 and 6 in the form of thin and thicker films in the magnitude of microns were prepared by spreading droplets of dilute solution in tetra-hydrofuran (THF) on aluminum foil pre-washed with alcohol and then with acetone. The specimens in thick slices ( 1 mm) B-6 (No. 4), K-5 (No. 7) and K-6 (No. 8) as described in ${ }^{[2]}$ are tested as received. The 'pseudo-in-situ' test method used in this work denotes that only one specimen at a fixed orientation was employed for absolute intensity measurement from room temperature up to $500^{\circ} \mathrm{C}$. All samples were heated outside the XPS chamber under the protection of argon atmosphere.

The intensity of the signal in C1s spectrum is generally used in absolute intensity, i.e. counts per second (cps), which depends very much on the experimental conditions, for example, thickness, orientation of the sample, flux of X-ray source, and so on. The relative intensity of the signal which is expressed by formula (1) is often preferred for better reproducibility. Regardless which one is adopted, both are based on the fact that the intensity of signal means the number of carbon atoms/unit area.

$$
\text { Relativeintensity }(\%)=(\text { absoluteintensity })_{\mathrm{f}}-(\text { absoluteintensity })_{\mathrm{i}}(\text { absoluteintensity })_{\mathrm{i}}
$$

where $i$ and $f$ denote initial and final, namely, before and after treatment, e.g. irradiation.

The intensity of this signal for polymers does change on heating. When a polymer degrades, the number of carbon atoms/unit area must be densified due to the loss of elements other than carbon, say, hydrogen. The intensity increases dramatically, in particular, when cross-linking takes place even though some of carbon atoms are volatilized off at high temperature. Apparently, one can not directly make a quantitative correlation between the relative intensity $\%$ and gel content $\%$, because they are unequally scaled and the temperature ranges of the measurements are quite different. A qualitative comparison of the two seems to be reasonable at any rate.

\section{Results and discussion}

\subsection{Prior to irradiation}

The relative intensity in the C1s spectra is related to the accumulation of carbon in the solid phase [4], [5]. Fig. 1 shows the relative intensity curves derived from Cls spectra of 
polybutadiene and polystyrene as a function of temperature. Each curve is ratioed against the amount of carbon which is inherently present in the sample. A decrease in carbon intensity means that carbon is lost while an increase in carbon intensity means carbon is retained while other elements are lost. For polybutadiene (PBD) there are three steps which cover the entire range of temperature from 25 to $500^{\circ} \mathrm{C}$. In the first step, $25-180^{\circ} \mathrm{C}$, a loss of carbon is indicated. The relative intensity in the second step, $180-400^{\circ} \mathrm{C}$, shows a small increase; in the last step, $>400^{\circ} \mathrm{C}$, a large increase in intensity is observed. The first step is primarily due to the presence of surface contamination (adventitious carbon) which can be removed by heating or by other means, for example, irradiation. It indicates a weak accumulation of carbon and a corresponding loss of other elements. The charring process begins at the minimum, ca. $180^{\circ} \mathrm{C}$, in the negative region and continues to $400^{\circ} \mathrm{C}$. The minimum in the negative region can be visualized as the on-set of carbonization which must be related to the onset of the degradation process and this is observed at a temperature about $260^{\circ} \mathrm{C}$ lower than the onset temperature, $T_{10 \%}\left(439^{\circ} \mathrm{C}\right)$, measured by TGA experiments ${ }^{[2]}$. The difference must arise from the much higher sensitivity of XPS technique relative to that of TGA. The obvious increase in carbonization starting above $400^{\circ} \mathrm{C}$ is reasonably ascribed to the cyclization reaction [2].

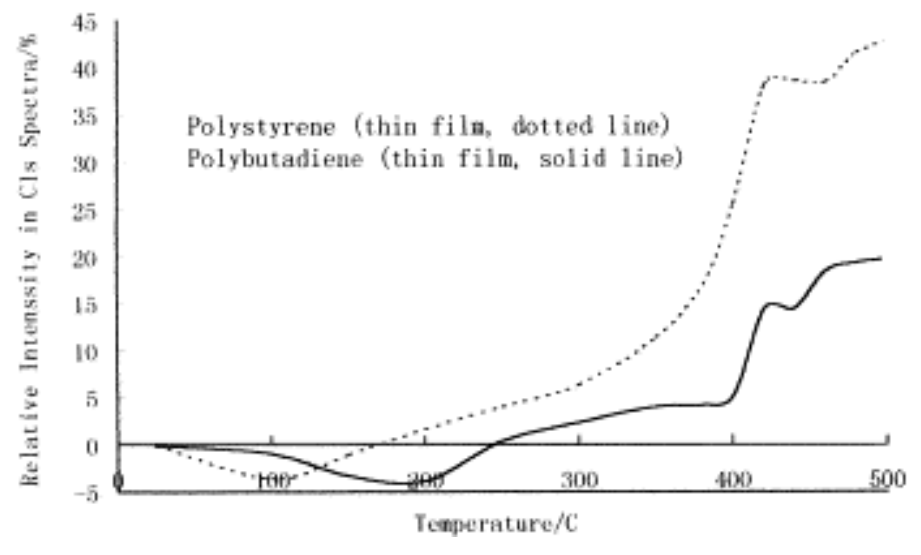

Fig. 1. Relative intensity of polystyrene (thin film, dotted line) and polybutadiene (thin film, solid line) vs temperature.

For polystyrene four steps can be clearly seen in the figure. The first step, $25-100^{\circ} \mathrm{C}$, is again due to surface contamination. The on-set temperature of carbon accumulation begins at ca. $100^{\circ} \mathrm{C}$ corresponding to the minimum, which is lower by about $250^{\circ} \mathrm{C}$ than the onset temperature of degradation, $T_{10 \%}\left(346^{\circ} \mathrm{C}\right)^{[2]}$, reported by Schnabel et al. In the second step, $100-300^{\circ} \mathrm{C}$, carbonization is slowly increasing, $<6 \%$. A dramatic increase is seen in the third step, $300-420^{\circ} \mathrm{C}$, reaching $40 \%$ at $420^{\circ} \mathrm{C}$. The carbonization reaction levels off in the fourth step, $>420^{\circ} \mathrm{C}$. In this fourth step the carbon which has accumulated earlier is lost. The thermal degradation of $\mathrm{PS}$ begins at about $300^{\circ} \mathrm{C}$ and almost everything has volatilized at $400^{\circ} \mathrm{C}$ by TGA. Apparently, a highly carbonized network is produced in the condensed phase even though chain scission dominates the chemistry leading to the formation of a large amount of monomer and other volatiles within the third step. Polystyrene displays a much higher rate and extent of char formation in the condensed phase compared to polybutadiene even though the former is less thermally stable than the latter. 
Two curves for copolymers SBS (75\%BD) and K-resin (25\%BD) are shown in Fig. 2. Ignoring surface contamination, which gives the negative initial peak, the main feature of each consists of two peaks. In case of SBS the peak at higher temperature corresponds to a peak of butadiene nature while the lower temperature feature corresponds to a styrene feature. The maxima at $438^{\circ} \mathrm{C}, \mathrm{SBS}$, and $387^{\circ} \mathrm{C}$, K-resin, may be attributed to the cyclization reaction which has previously been reported for these materials and which have also been observed by DSC in the study by Schnabel ${ }^{[2]}$. As explained above, the minima taking place in the negative regions at about $150^{\circ} \mathrm{C}, \mathrm{K}$-resin, and $180^{\circ} \mathrm{C}$, SBS, correspond to their onset temperatures of thermal degradation. This shows that the K-resin is less stable than SBS by about $30^{\circ} \mathrm{C}$. It seems to be true that a large amount of BD existing in the system would render the system more stable. Above $420^{\circ} \mathrm{C}$ the curve for K-resin once again goes in the negative direction, although this is different in nature from surface contamination. This is indicative of the disappearance of the carbonaceous char at high temperatures. The reason is due to the ease of volatilization of K-resin as confirmed from XPS experiments. Note that there is no such negative peak in case of SBS. Apparently, the carbonaceous char produced from K-resin is much less stable than that from SBS. In other words, the former is volatilized while the latter continues to accumulate. In order to make the explanation clear we show Fig. 3, Fig. 4. The comparison of polybutadiene with SBS (Fig. 3) and polystyrene with K-resin (Fig. 4) allow us to relate their properties, such as, thermal stabilities and char-forming tendencies, to contributions from the constituents.

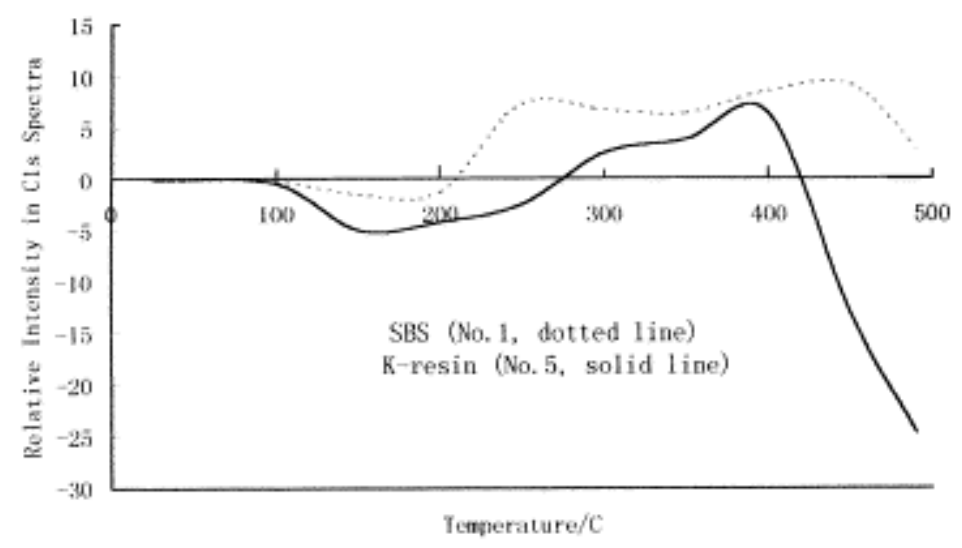

Fig. 2. Relative intensities of copolymers SBS (No. 1, thin film, dotted line) and K-resin (No. 5, thin film, solid line) vs temperature.

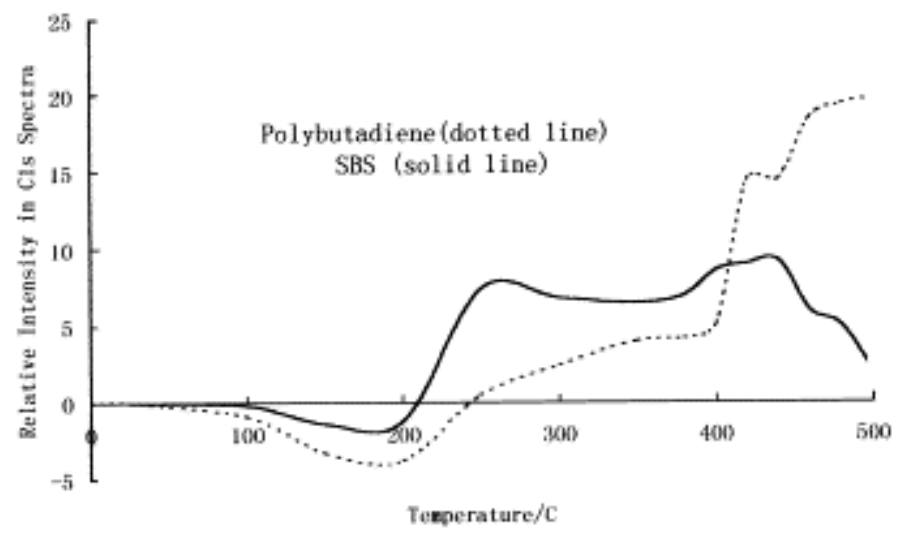


Fig. 3. Relative intensity of PBD (thin film, dotted line) and SBS (No. 1, thin film, solid line) vs temperature.

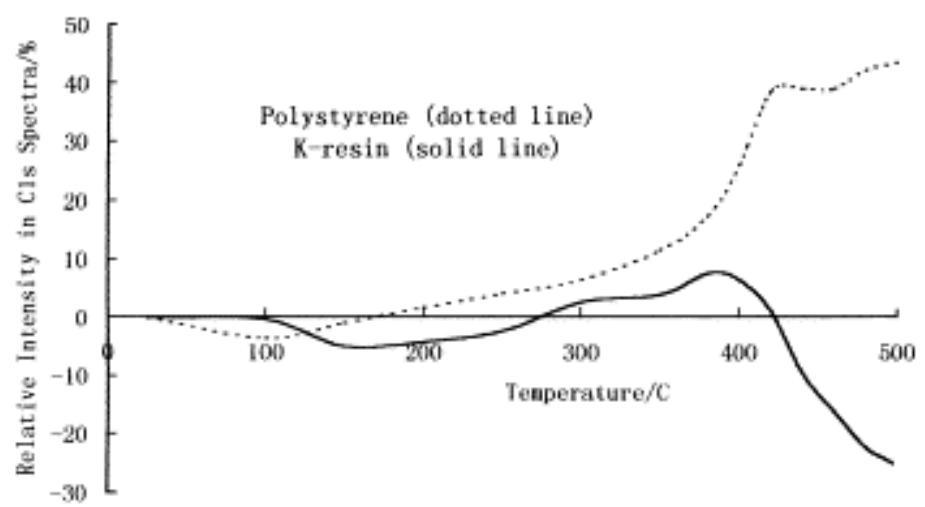

Fig. 4. Relative intensity of PS (thin film, dotted line) and K-resin (No. 5, thin film, solid line) vs temperature.

\subsection{Effect of irradiated dose on char formation}

Based on gel content under both anoxic and oxic conditions Schnabel et al. [2] found that radiation-induced cross-linking occurring in the two copolymers depends greatly on the irradiated dose absorbed by the samples prior to heating. In order to understand these results the following pseudo-in-situ XPS experiments have been performed. For sample Nos. 1-8 all XPS data (anoxic) on the extent of cross-linking versus temperature are listed in Table 1.

Table 1. XPS data (anoxic) on the extent of cross-linking vs temperature

Relative intensity (\%) in C1s spectra as function of temperature for SBS copolymers

No. 1 thin film, No. 2 thicker film, No. 3* thin film, unirradiated unirradiated 0.04 MGylair

No. 4 B-6 (slice)

\begin{tabular}{|c|c|c|c|c|c|c|c|c|}
\hline \multirow[b]{2}{*}{$\begin{array}{c}\text { Temerpature } \\
\left({ }^{\circ} \mathrm{C}\right)\end{array}$} & \multicolumn{2}{|c|}{ unirradiated } & \multicolumn{2}{|c|}{ unirradiated } & \multicolumn{2}{|c|}{ 0.04 MGylair } & \multicolumn{2}{|c|}{0.15 MGy } \\
\hline & CPS & $\begin{array}{c}\text { Intensity } \\
\text { (\%) }\end{array}$ & CPS & $\begin{array}{c}\text { Intensity } \\
\text { (\%) }\end{array}$ & CPS & $\begin{array}{c}\text { Intensity } \\
\text { (\%) }\end{array}$ & CPS & \\
\hline $\begin{array}{l}\text { oom } \\
\text { mperature }\end{array}$ & $57,89 c$ & 0.0 & 57,590 & 0.0 & 48,190 & 0.0 & 40,288 & 30.0 \\
\hline 00 & 57,210 & -1.2 & 56,660 & -1.6 & 53,710 & 11.5 & 40,470 & 0.5 \\
\hline 00 & 61,800 & 6.8 & 60,900 & 5.7 & 55,840 & 15.9 & 42,230 & 4.8 \\
\hline 0 & 62,880 & 8.6 & 64,040 & 11.2 & 58,030 & 20.4 & 53,940 & 33 \\
\hline 90 & 59,580 & 2.9 & 67,500 & 2.9 & 61,000 & 27.2 & 63,540 & 57. \\
\hline
\end{tabular}

Relative intensity (\%) in C1s spectra as function of temperature for K-resin copolymers
No. 5 thin film un- No. 6a thicker film, No. $7 \mathrm{~K}-5$ (slice)
No. 8 K-6 (slice)
irradiated
0.04 MGy/air
$0.41 \mathrm{MGy} / \mathrm{Ar}$
$0.62 \mathrm{MGy} / \mathrm{Ar}$
Temperature
$\left({ }^{\circ} \mathrm{C}\right)$
Intensity CPS
(\%)
Intensity
(\%)
CPS
Intensity
(\%)
Intensity
(\%)

(\%) 
Relative intensity (\%) in C1s spectra as function of temperature for SBS copolymers No. 1 thin film, No. 2 thicker film, No. $3^{*}$ thin film, No. 4 B-6 (slice) unirradiated unirradiated 0.04 MGylair $0.15 \mathrm{MGylAr}$

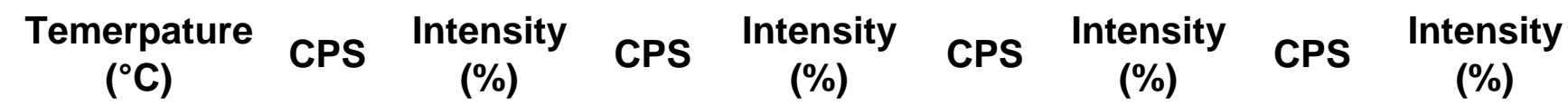

\begin{tabular}{|c|c|c|c|c|}
\hline $\begin{array}{l}\text { Room } \\
\text { temperature }\end{array}$ & $61,8400.0$ & $\begin{array}{lll}57,960 & 0.0\end{array}$ & $49,9600.0$ & $32,9000.0$ \\
\hline 200 & $59,270-4.2$ & $61,2805.7$ & $51,1502.4$ & $44,19034.3$ \\
\hline 300 & $63,4302.6$ & $64,33011.0$ & $51,4403.0$ & $47,80045.3$ \\
\hline 400 & $65,4006.4$ & $65,23012.5$ & $53,72022.5$ & $50,90054.7$ \\
\hline 490 & $46,550-24.7$ & $58,420 \quad 0.8$ & $64,38028.9$ & $60,88085.0$ \\
\hline
\end{tabular}

alrradiated under air (oxic).

A graphical representation of these data is shown in Fig. 5, Fig. 6, Fig. 7, Fig. 8. The following conclusions may be drawn from these data:

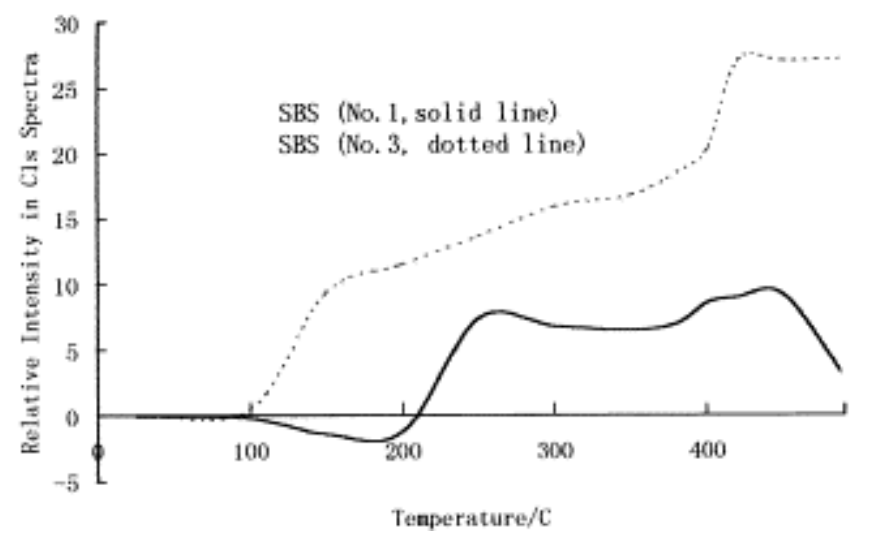

Fig. 5. Relative intensity of SBS (No. 1, unirradiated, solid line) and SBS (No. 3, dotted line, 0.04 MGy).

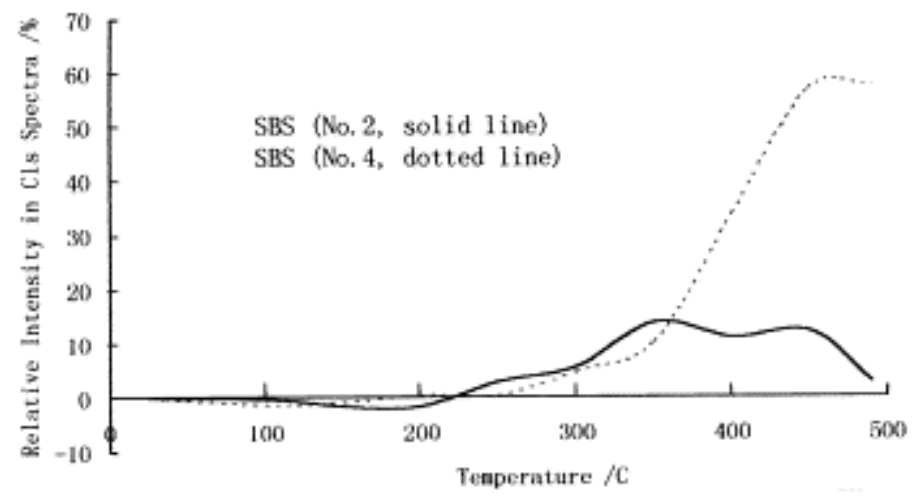

Fig. 6. Relative intensity of SBS (No. 2, unirradiated, thicker film, solid line) and SBS (No. 4, slice, 0.15 MGy, dotted line). 


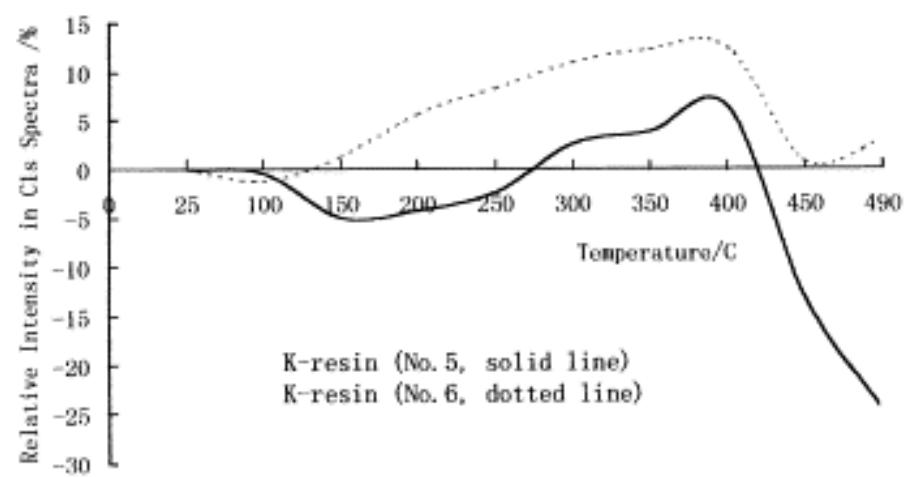

Fig. 7. Relative intensity of K-resin (No. 5, unirradiated, thin film, solid line and K-resin (No. 6, thin film, 0.04 MGy, dotted line).

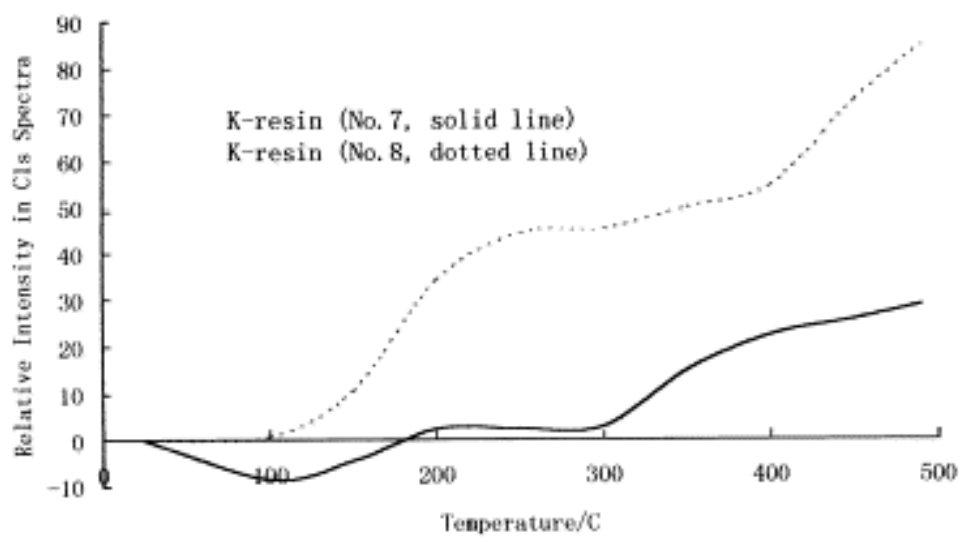

Fig. 8. Relative intensity of K-resin (No. 7, 0.41 MGy, slice, solid line) and K-resin (No. 8, 0.62 MGy, slice, dotted line).

There is no surface contamination on the irradiated samples, i.e. irradiation removes the adventitious contaminants; as the irradiation dose increases the extent of carbonization also increases as seen in the increased intensity at each temperature; and at a given level of irradiation, the higher the temperature, the higher is the amount of carbonization. The maximum extent of carbonization may be read from Fig. 5, Fig. 6, Fig. 7, Fig. 8 and these are tabulated in Table 2.

Table 2. Effect of irradiation on extent of cross-linking

\section{Sample Extent of cross-linking (\%) before irradiation \\ Extent of cross-linking (\%) after irradiation (dose)}

SBS (thin film) e- 9.0

beam

SBS (thin film) $Y-14.0$

ray

K-resin (thin

7.5

film), e-beam
28 (0.04 MGy)

Fig. 5

58 (0.15 MGy)

Fig. 6

14 (0.04 MGy)

Fig. 7 


\section{Sample Extent of cross-linking (\%) before irradiation \\ Extent of cross-linking (\%) after irradiation (dose) \\ Comment}

K-resin (slice), $\mathrm{Y}^{-}$-

26 (0.41 MGy)

Fig. 8

ray

K-resin (slice), $\mathrm{Y}^{-}$-

ray
87 (0.62 MGy)

Fig. 8

These XPS data confirm the speculation offered by Schnabel, that is, radiation-induced crosslinks do not affect the thermal behavior of polystyrene and the radiation-induced chemical alterations play a minor role during the thermal degradation of polybutadiene.

It is necessary to compare samples of similar thickness in order to come to a conclusion and these samples show some variation in thickness, so the conclusion must be tentative.

\subsection{Effect of irradiated dose on chemical structure of char}

We now address the connection between irradiation and the chemical structure of char residues and it is quite appropriate that a parameter which is inherently related to char formation is involved. The chemical states of different systems can often be rationalized in terms of the energy loss (plasmon) $\Delta E_{\mathrm{LS}}$ in Cls spectra. This energy loss $\Delta \mathrm{E}_{\mathrm{L}}$ is defined as the splitting between the principal line and its largest companion loss peak $E_{\mathrm{L}}$ in the Cls spectra. This is the one parameter which can be abstracted from Cls spectra that is independent of charging and relaxation effect, which are of significance in XPS experiments. The size of the splitting $\Delta E_{\mathrm{L}}$ is directly dependent upon the chemical state of the system. For genuine graphite, for example, the loss splitting $\Delta E$ L should essentially duplicate the free electron plasmon calculated result of $\sim 31 \mathrm{eV}$. Variations from this value may be indicative of a reduction in graphitic character $[6]$, and suggest a reduction in the degree of total delocalized conjugation.

The $\Delta E$ LS are normally in the range of $21-22 \mathrm{eV}$ at ambient temperature for polymers as determined by Barr et al. ${ }^{77}$. As expected, the magnitude of $\Delta E_{L}$ is temperature dependent as shown in XPS experiments which should be performed at similar thickness. In this case it is not possible to have the same thickness for all samples, so one must be careful in drawing conclusions. The increase in $\Delta E \mathrm{LS}$ implies a greater extent of graphitization occurring in the polymeric matrix. Values for some polymers such as LDPE/HDPE, PVC and PVC/transition metal systems have been measured by anoxic XPS in the laboratory at a temperature ( $\left.L T_{\mathrm{GRL}}\right)$ at which charring just begins [4], [5]. What is required is the nature of the charred residues as function of temperature. Data on samples B-6 (No. 4), K-5 (No. 7) and K-6 (No. 8) are collected in Table 3 and Fig. 9. 
Table 3. XPS data (anoxic) on the nature of the charred residues vs temperature

Energy loss $\Delta E L$ in C1s spectra as function of temperature for SBS copolymers

No. 1 thin film, unirradiated

\section{Temperature \\ $\left({ }^{\circ} \mathrm{C}\right)$}

Room

temperature

200

300

400

490
$\Delta E_{\mathrm{L}}(\mathrm{eV})$
22.2

22.7

23.4

23.6

26.7
No. 2 thicker film unirradiated

$\Delta E_{\mathrm{L}}(\mathrm{eV})$
No. 3 thin film, No. 4 B-6 (slice)

0.04 MGylair

$\Delta E_{\mathrm{L}}(\mathrm{eV})$
$0.15 \mathrm{MGylAr}$

$\Delta E_{\mathrm{L}}(\mathrm{eV})$
22.4

22.8

23.4

23.3

26.7
21.8

22.9

23.1

23.4

27.6
21.9

22.1

22.1

23.5

24.8

Energy loss $\Delta E_{L}$ in C1s spectra as function of temperature for SBS copolymers

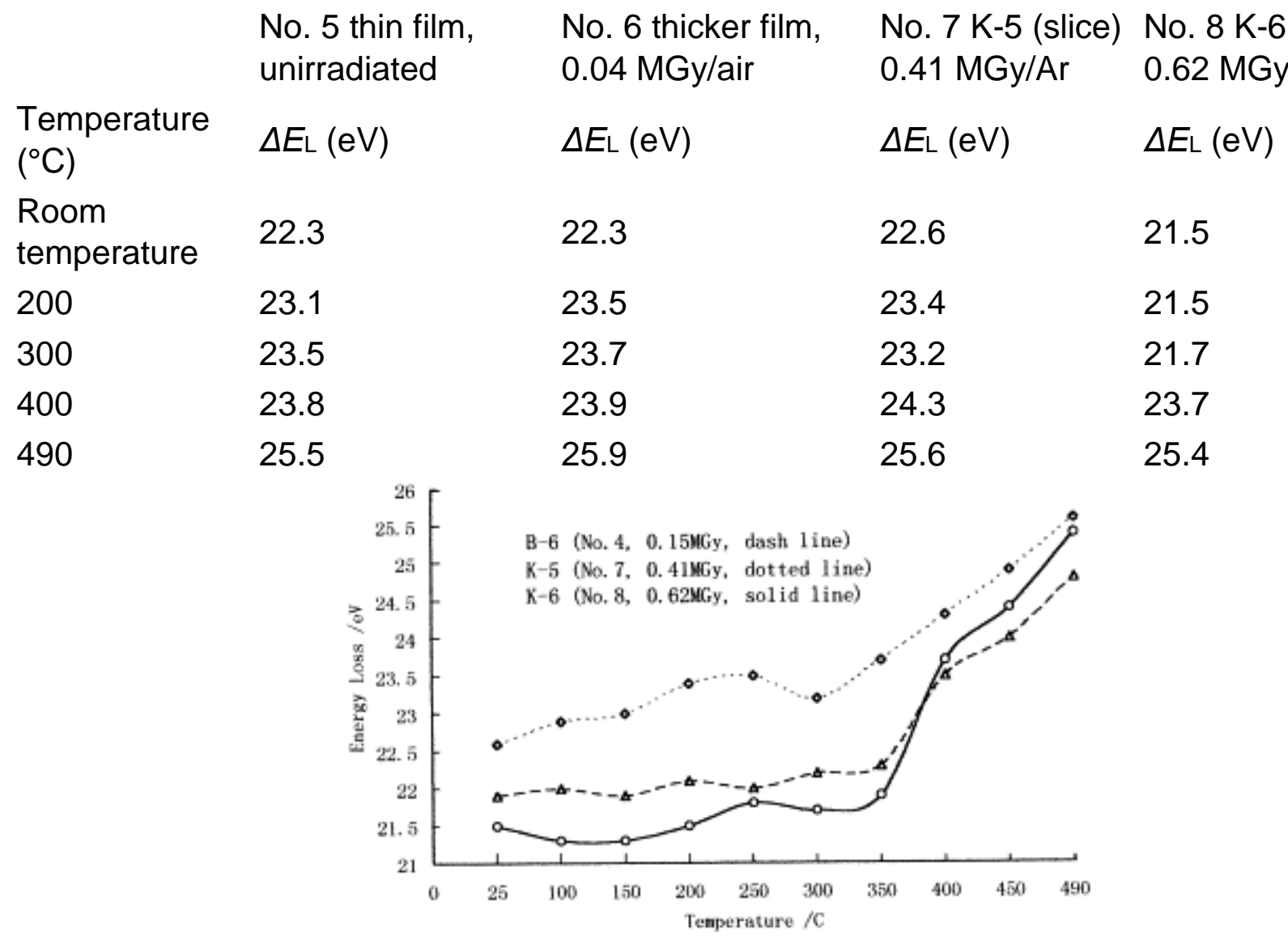

Fig. 9. Energy loss ( $\Delta \mathrm{E}$ L of B-6 (No. 4, 0.15 MGy, dashed line), K-5 (No. 7, 0.41 MGy, dotted line) and K-6 (No. 8, 0.62 MGy, solid line).

One can see for every sample that the extent of graphitization increases with temperature. At temperature of $L T_{\text {GRL }}$ the value of energy loss $\Delta E_{L S}$ is in a range of $23.5-25.5 \mathrm{eV}$ [8], much less than the $31.0 \mathrm{eV}$ expected for the well ordered graphite which can only be obtained at 
temperature above $2000^{\circ} \mathrm{C}$. This means that char formation begins with a graphite-like structure consisting of a large number of disordered domains. The actual structure of the char is rather far removed from a graphitic structure. At a given temperature the degree of graphitization does not increase as function of irradiation energy but actually decreases. This indicates that temperature alone is more important in the graphitization process and that irradiation can actually retard graphitization. Similar results were found by Schnabel.

Interesting features can be abstracted from Fig. 9. Each curve consists of two steps within the entire range of temperature, with the first step ending at about $350^{\circ} \mathrm{C}$ and the second step between 350 and $500^{\circ} \mathrm{C}$.

For both K-resin samples the growth rate versus temperature of the sample K-6 irradiated with $0.62 \mathrm{MGy}$ dose seems to increase at a greater rate than K-5 irradiated with $0.41 \mathrm{MGy}$ dose even though the $\Delta E \mathrm{~L}$ of K-6 (No. 8) shows a smaller value than K-5 (No. 7) in the first step. In other words the reduction in $\Delta E \mathrm{~L}$ induced by higher dose for $\mathrm{K}-6$ in the first step seems to retard the degradation but it also enhances the charring process in the second step.

If one assumes that $\Delta E \mathrm{~L}$ equals $25.4 \mathrm{eV}$ at the on-set of charring, one can extract the limiting transformation temperature of graphite-like structure $L T_{\text {GRL }}$ from either Table 3 or Fig. 9 , and this information is shown in Table 4 at the same thickness. It appears that a large dose of radiation leads to a higher $L T_{\mathrm{GRL}}$, implying that the charring can be retarded by a large dose of radiation.

Table 4. The $L T_{\mathrm{GRL}}$ of PS, PBD and copolymers by XPS experiments (assuming $\Delta E_{\mathrm{L}}=25.4 \mathrm{eV}$ to be the on-set of charring)

\section{Unirradiated polystyrene (thin film): $>500^{\circ} \mathrm{C}$ Unirradiated polybutadiene (thin film): $>500^{\circ} \mathrm{C}$ SBS (75\% BD) copolymers}

Thin film $\rightarrow$ thick film No. 1. (unirradiated): $440 \rightarrow$ No. 3 (0.04 Mgy): 450

Thick film $\rightarrow$ slice $\quad$ No. 2 (unirradiated): $473 \rightarrow$ No. 4 (B-6) (0.15 Mgy): $>490$

K-resin $(25 \%$ BD) copolymers

Thin film $\rightarrow$ thick film No. 5 (unirradiated): $450 \rightarrow$ No. 6 (0.04 Mgy): 470

Slice $\rightarrow$ slice $\quad$ No. 7 (K-5) (0.41 Mgy): $470 \rightarrow$ No. 8 (K-6) (0.62 MGy): 485

The crosslink density attained by irradiation does increase compared to that achieved by thermal cross-linking induced by heating the sample during pseudo-in-situ XPS experiment. In cases of PS, PBD and copolymers SBS/K-resin, cross-linking induced by irradiation may lead to char formation at high temperature even though it shows only a small or no effect on the onset temperature of degradation. 


\section{Conclusion}

XPS can be used to study the char formation in polymers such as PS, PBD and copolymers of these. The pseudo-in-situ XPS approach permits an understanding of the accumulation of carbon as function of temperature.

References

[1] C.A. Wilkie, S.J. Sirdesai, T. Suebsaeng, P.-H. Chang Fire Safety Journal, 15 (1989), pp. 297-311

[2] Schnabel W, Levchik GF, Wilkie CA, Jiang DD, Levchik SV. Polym Degrad Stab 1999;63:365.

[3] P.J. Flory, J. Renner J. Chem. Phys., 11 (1943), p. 512

[4] Wang J. In: Nelson GL, editor. Fire and polymers II, materials and tests for hazard prevention. (ACS Symposium Series 599). Washington DC: American Chemical Society, 1995. p. 518-35.

[5] Wang J. In: Le Bras M, Camino G, Bourbigot S, Delobel R, editors. Fire Retardancy of Polymers, The Use of Intumescnece. UK: Royal Society of Chemistry, 1998. p. 159-72.

[6] D. Pines Rev. Mod. Phys., 28 (1956), p. 184

[7] T.L. Barr, M. Yin J. Vac. Sci. Technol, A, A10 (4) (1992), p. 1788

[8] Li B. Ph.D. thesis, Beijing Institute of Technology, 1997. 